\title{
Effects of extracts of high- and low-chromium brewer's yeast on metabolism of glucose by hepatocytes from rats fed on high- or low-Cr diets
}

\author{
BY E.S. HOLDSWORTH AND E. NEVILLE* \\ Biochemistry Department, University of Tasmania, GPO Box 252C, Hobart, Tasmania 7001, \\ Australia
}

(Received 30 March 1989 - Accepted 18 December 1989)

\begin{abstract}
Brewer's yeast was grown on a defined medium containing glucose, ammonia, salts and vitamins plus tracer ${ }^{51} \mathrm{Cr}$ without (low-Cr) or with (high-Cr) carrier $\mathrm{Cr}$. The two batches of yeast differed by more than 100-fold in $\mathrm{Cr}$ content, containing $80 \mathrm{ng}$ and $10 \mu \mathrm{g} \mathrm{Cr} / \mathrm{g}$ dry yeast respectively. Extraction and fractionation procedures were designed to isolate $\mathrm{Cr}$ complexes with properties similar to those reported for glucose tolerance factor. After weaning, rats were reared on rat cubes (normal diet) or on a diet containing less than $0.1 \mu \mathrm{g} \mathrm{Cr} / \mathrm{kg}$ (low-Cr diet), or on the low-Cr diet supplemented with $\mathrm{Cr}$ $(1 \mathrm{mg} \mathrm{Cr} / \mathrm{kg})$. Hepatocytes from these rats were incubated with $\left[\mathrm{U}-{ }^{14} \mathrm{Clglucose}\right.$ and incorporation of ${ }^{14} \mathrm{C}$ into glycogen was measured. Incorporation of glucose- $\mathrm{C}$ into glycogen was enhanced by some yeast fractions in the presence of insulin, but had less effect in the absence of insulin. No difference could be detected between the responses to fractions from high- or low-Cr yeast extracts, or between responses by hepatocytes from animals fed on normal or low- $\mathrm{Cr}$ diets with or without $\mathrm{Cr}$ supplementation. Glycogen synthetase (EC 2.4.1.11) activity (total and percentage in the $a$ form) was similar in hepatocytes isolated from animals on the normal and low-Cr diets. Those yeast fractions which enhanced the response to insulin in the ${ }^{14} \mathrm{C}$-incorporation experiments also enhanced the percentage of the enzyme in the $a$ form in the presence of insulin, but not in the absence of insulin. The presence in yeast extracts of material which enhances the response to insulin by hepatocytes may help to explain the reported beneficial effects of dietary yeast supplements on glucose tolerance.
\end{abstract}

Brewer's yeast: Chromium: Glucose metabolism: Rat

It has been proposed that chromium complexes have a role in glucose metabolism, and that some cases of glucose intolerance may be due to a deficiency of $\mathrm{Cr}$ (Mertz, 1976). This concept arose from experiments in which rats were raised on a diet composed of $300 \mathrm{~g}$ Torula yeast plus $600 \mathrm{~g}$ sucrose $/ \mathrm{kg}$, plus lard, vitamins and minerals (Schwarz, 1951). Such rats were slow to clear a glucose load from their blood, and this symptom was rapidly relieved by giving extracts of brewer's yeast or pig kidney, or more slowly by giving $\mathrm{Cr}^{3+}$ compounds (Schwarz \& Mertz, 1959). Attempts were made to isolate from brewer's yeast the active principle, which was called glucose tolerance factor (GTF), and it was claimed that GTF was a low-molecular-weight cationic complex of $\mathrm{Cr}^{3+}$, nicotinic acid and amino acids. Such complexes have never been isolated from yeast in pure form. Active yeast fractions or synthetic $\mathrm{Cr}$ complexes were found to enhance glucose utilization by isolated adipocytes in the presence of low concentrations of insulin, but not in the absence of insulin (Toepfer et al. 1977). Some evidence suggests that dietary supplements of high-Cr yeast are beneficial to some humans with hyperglycaemia, but results of supplementation with $\mathrm{Cr}$ salts have been less clear-cut (Vinson \& Bose, 1984; Vinson \& Hsaio, 1985; Wallach, 1985; Offenbacher \& Pi-Sunyer, 1988).

\footnotetext{
* For reprints.
} 
The aim of the present work was to search for $\mathrm{Cr}$ complexes in yeast and to examine their effects on glucose metabolism by rat liver. The liver has a unique role in glucose homeostasis, and may be quantitatively of more importance in disposal of a glucose load than is adipose tissue, which has been used as a test system for GTF preparations. Isolated hepatocytes retain the ability to act as a glucostat under appropriate conditions (Davidson, 1981), and so the effects of yeast fractions on glucose metabolism by isolated hepatocytes in the presence and absence of insulin have been measured. Extracts have been prepared from both high- and low-Cr yeast, and have been tested on hepatocytes from rats reared on rat cubes or on a low-Cr diet similar to that of Schwarz (1951).

\section{EXPERIMENTAL METHODS}

Growth and fractionation of brewer's yeast

Brewer's yeast was grown on a defined medium of glucose, ammonium sulphate, vitamins and minerals as described by Davies et al. (1985), using double glass-distilled water and the purest chemicals available. Two 20 litre batches were grown, a low-Cr batch with only tracer ${ }^{51} \mathrm{Cr}\left(5 \mathrm{mCi}, 208 \mu \mathrm{g} \mathrm{Cr}{ }^{3+}\right)$ and the other a high-Cr batch with $5 \mathrm{mCi}{ }^{51} \mathrm{Cr}$ plus $20 \mathrm{mg} \mathrm{Cr}^{3+}$ (as acetate). Both batches yielded $100 \mathrm{~g}$ dry weight of yeast containing $80 \mathrm{ng}$ and $10 \mu \mathrm{g} \mathrm{Cr} / \mathrm{g}$ respectively.

Extraction of the yeasts with $0.5 \mathrm{M}$-ammonia and fractionation on Biogel P4, DEAE Sephadex A25 and Dowex $50 \times 8$ in the $\mathrm{H}^{+}$form was done essentially as previously described by Davies et al. (1985) and summarized in Fig. 1. Fractions were selected for further study, initially on the basis of ${ }^{51} \mathrm{Cr}$ content and on the yeast assay for GTF (Holdsworth \& Appleby, 1984), and later on the basis of the response by hepatocytes.

Atomic absorption at $357.9 \mathrm{~nm}$ was used to estimate $\mathrm{Cr}^{3+}$ with a Varian Techtron Model 100 fitted with a deuterium square-wave-modulated background corrector. Soluble fractions were assayed directly but yeast was wet-ashed in 10-ml Kjeldhal flasks using concentrated nitric acid (Suprapur, Merck). None of the materials from yeast grown on tracer amounts of ${ }^{51} \mathrm{Cr}$ had sufficient $\mathrm{Cr}$ to estimate by this technique, therefore $\mathrm{Cr}$ was estimated from the radioactivity of ${ }^{51} \mathrm{Cr}$ measured in a sodium iodide gamma counter (Kontron MR252) with an efficiency of $10.6 \%$. The specific activity of ${ }^{51} \mathrm{Cr}$ used in the calculation was that given by the suppliers (New England Nuclear, Searle Nucleonics, Sydney).

\section{Animals and diets}

Hooded Wistar male rats fed on commercial rat cubes were used for most of the experiments. Rats were also raised from weaning (approximately $50 \mathrm{~g}$ ) on the low-Cr diet similar to that of Schwarz (1951). The diet supplied by Teklad (Wisconsin, USA) contained $300 \mathrm{~g}$ Torula yeast $/ \mathrm{kg}, 600 \mathrm{~g}$ sucrose $/ \mathrm{kg}$, plus lard, vitamins, minerals and amino acids (Teklad 84485). Amino acids were included (L-cystine, L-methionine and L-histidine to give $3 \cdot 0,3 \cdot 7$ and $2 \cdot 1 \mathrm{~g} / \mathrm{kg}$ respectively) because earlier work had suggested that the amino acid balance of a diet containing $300 \mathrm{~g}$ Torula yeast $/ \mathrm{kg}$ as the only source of protein was not quite suited to rats (Sherriff, 1983). Neutron activation analysis showed that this diet contained less than $0 \cdot 1 \mu \mathrm{g} \mathrm{Cr} / \mathrm{g}$. Attempts were made to minimize contamination with $\mathrm{Cr}$ by the use of plastic cages with raised aluminium-mesh floors, aluminium food dishes and provision of deionized drinking water in all-glass containers. Room air was not filtered. Rats grown under these conditions were probably only marginally deficient in $\mathrm{Cr}$ as severe $\mathrm{Cr}$ deficiency can only develop under strictly controlled environmental conditions as described by Schroeder (1966). However, marginal Cr deficiency is sufficient to produce 


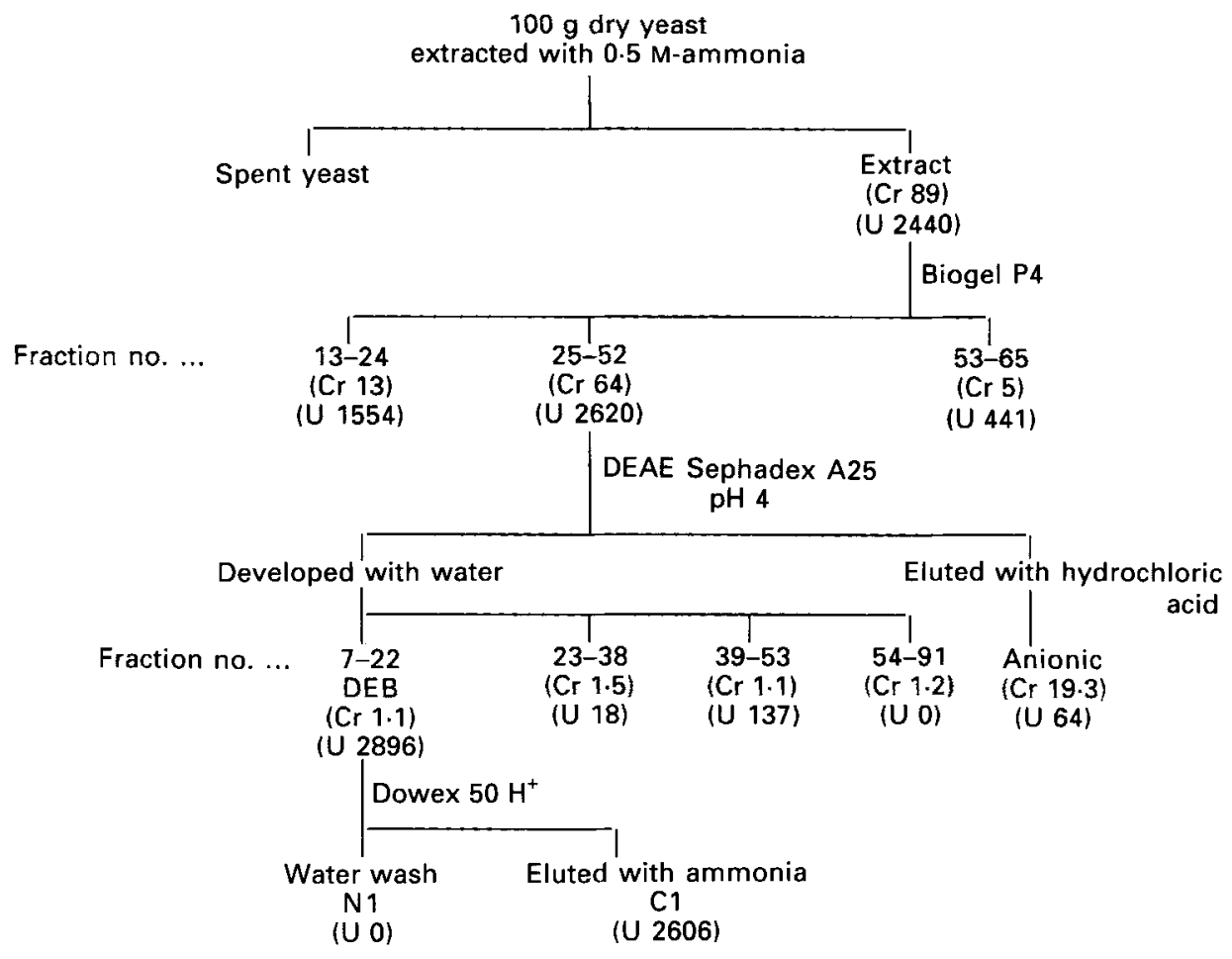

Fig. 1. Fractionation of brewer's yeast. DEB, $\mathrm{Cl}$ and $\mathrm{N} 1$ are fractions obtained. The values in parentheses are the percentage of the yeast chromium which was recovered $(\mathrm{Cr})$, and the number of units of activity (U) in the yeast assay for glucose tolerance factor (Holdsworth \& Appleby, 1984).

adipose tissue eliciting a response to GTF (Anderson et al. 1978). Some rats were fed on this same low-Cr diet supplemented with $1 \mathrm{mg} \mathrm{Cr} / \mathrm{kg}$. Lighting was provided from 06.00 to 18.00 hours. The rats were used when they each weighed approximately $200 \mathrm{~g}$.

\section{Isolation and incubation of hepatocytes}

Hepatocytes were isolated by a modification of the method of Krebs et al. (1974) from rats which had been fed ad lib. Of the cells 90-95\% excluded trypan blue. The ATP level was 8.9 (SE 0.3 ) $\mu \mathrm{mol} / \mathrm{g}$ dry weight and was $75 \%$ of total adenine nucleotides. Cells, $20 \mathrm{mg}$ dry weight in a total volume of $4 \mathrm{ml}$, were incubated in stoppered 25 -ml flasks in Krebs-Ringer bicarbonate containing $25 \mathrm{~g}$ dialysed defatted bovine serum albumen/l and $20 \mathrm{mM}$-glucose under oxygen-carbon dioxide $(95: 5, \mathrm{v} / \mathrm{v})$ at $37^{\circ}$, and shaken at $100 \mathrm{rev} . / \mathrm{min}$. Additions, as shown in the tables, were made in small volumes at $\mathrm{pH} 7 \cdot 4$; when added, insulin was present at $4 \mathrm{~nm}$ except where stated otherwise; amounts of yeast fractions were equivalent to $4.5 \mathrm{mg}$ yeast. For incorporation experiments the glucose was labelled with $\left[\mathrm{U}^{14} \mathrm{C}\right] \mathrm{glucose}\left(2 \times 10^{6}\right.$ disintegrations/min per $4 \mathrm{ml}$ ), and reactions were stopped at $60 \mathrm{~min}$ by the addition of perchloric acid to give a concentration of $0.3 \mathrm{M}$.

\section{Isolation of glycogen}

The acidified incubation mixture was incubated at $37^{\circ}$ for $1 \mathrm{~h}$ to extract glycogen. After centrifugation at room temperature, carrier glycogen was added to the supernatant fraction $(25 \mathrm{mg} / \mathrm{ml})$ and glycogen was precipitated with ethanol $(660 \mathrm{~g} / \mathrm{l})$. After storage at $-15^{\circ}$, 
the glycogen was sedimented, dissolved in water containing unlabelled glucose and reprecipitated with ethanol. It was then filtered, washed on the filter with ethanol $(700 \mathrm{~g} / 1)$ containing glucose, dissolved in water and counted. Rates of incorporation of precursor ${ }^{14} \mathrm{C}$ were calculated as $\mu \mathrm{g}$ atoms $\mathrm{C} / \mathrm{min}$ per $\mathrm{g}$ dry weight of hepatocytes, using the value of the specific activity of the labelled precursor at zero time. Radioactivity in samples was measured in Packard ACSII Scintillation Cocktail using a multi-channel $\beta$-scintillation counter (Beckman 3801) appropriately programmed for quenching.

\section{Estimation of glycogen synthetase (EC 2.4.1.11)}

Cells were incubated with unlabelled glucose with or without $4 \mathrm{nM}$-insulin and the additions shown. After $40 \mathrm{~min}$ incubation, hepatocyte suspensions were centrifuged and the cell pellets frozen in liquid nitrogen and stored overnight at $-80^{\circ}$. The pellets were thawed and mixed with ice-cold medium (10 mM-EDTA, $100 \mathrm{~mm}-\mathrm{NaF}, 10 \mathrm{~mm}$-Tris hydrochloride (pH 7.1), $20 \mathrm{~g}$ Triton X-100/1) and centrifuged at $10000 \mathrm{~g}$ for $1 \mathrm{~min}$. Glycogen synthetase in the supernatant fraction was assayed by the method of Thomas et al. (1968) in the presence (total or $a+b$ ) and the absence $(a)$ of glucose-6-phosphate.

\section{Estimation of metabolites}

Glycogen was extracted from acidified cell suspensions as described previously, and estimated by the method of Lee \& Whelan (1966). Amino acids were estimated in yeast fractions by the method of Mokrasch (1967). Glucose-6-phosphate and adenine nucleotides were estimated in neutralized hepatocyte extracts by enzymic methods (Bergmeyer, 1974).

\section{RESULTS}

Effects of yeast fractions on incorporation of glucose-C into glycogen by hepatocytes from normal rats

Fig. 1 shows the fractionation of brewer's yeast grown in the presence of $1 \mathrm{mg} \mathrm{Cr} / \mathrm{l}$, the distribution of ${ }^{51} \mathrm{Cr}$ in the fractions, and the activities of fractions in the yeast assay for GTF. A similar distribution of ${ }^{51} \mathrm{Cr}$ and activities in the yeast assay were found in the fractions from the low-Cr yeast. Fractions 25-52 of the Biogel P4 filtrate contained most of the ${ }^{51} \mathrm{Cr}$ in a single peak. By comparison with the reference marker vitamin $\mathrm{B}_{12}\left(V_{\mathrm{e}} / V_{\mathrm{o}}\right.$ $=2 \cdot 50$ ), material in this peak (centre of peak $V_{\mathrm{e}} / V_{\mathrm{o}}=3 \cdot 70$ ) had a molecular weight less than 1300 , i.e. the molecular-weight range in fractions $25-52$ was similar to that which has been claimed for GTF (Mertz et al. 1974). After adsorption to DEAE Sephadex, only about $38 \%$ of the ${ }^{51} \mathrm{Cr}$ which was applied to the column was recovered even after elution with $1 \mathrm{M}-$ hydrochloric acid, and more drastic methods of elution were not attempted as it seemed likely that they would destroy $\mathrm{Cr}$ complexes. However, results from the yeast assay for GTF showed that inhibitory material was removed by Biogel, and that $119 \%$ of the activity which was applied to DEAE Sephadex was recovered in the combined eluates, $93 \%$ being in fraction DEB. Most of the yeast GTF activity of fraction DEB was recovered in fraction C1.

Table 1 shows that 4 nM-insulin gave less than half-maximal stimulation of ${ }^{14} \mathrm{C}$ incorporation into glycogen by these isolated hepatocytes. Concentrations of insulin down to $1 \mathrm{nM}$ gave a detectable increase, but $4 \mathrm{~nm}$-insulin was routinely used as it gave a measure of the responsiveness of each batch of hepatocytes. The anionic yeast fraction did not stimulate incorporation of glucose- $\mathrm{C}$ into glycogen by hepatocytes either in the presence or absence of insulin, and it was not studied further. Fraction DEB enhanced the response to low-insulin concentrations but had a much smaller effect in the absence of insulin. Further fractionation of DEB on Dowex 50 gave a 'neutral' fraction N1 which did not enhance the 
Table 1. Incorporation of glucose-carbon into glycogen by hepatocytes from rats which had been raised on various diets:

(Results are given as means with their standard errors; no. of replicates 4-12)

\begin{tabular}{|c|c|c|c|c|c|c|c|c|c|c|c|c|}
\hline \multirow[b]{3}{*}{ Additions } & \multicolumn{4}{|c|}{ Normal diet } & \multicolumn{4}{|c|}{ Low-chromium diet } & \multicolumn{4}{|c|}{$\begin{array}{l}\text { Low-Cr diet supplemented } \\
\text { with } \mathrm{Cr}\end{array}$} \\
\hline & \multicolumn{2}{|c|}{ - Insulin } & \multicolumn{2}{|c|}{+ Insulin } & \multicolumn{2}{|c|}{ - Insulin } & \multicolumn{2}{|c|}{+ Insulin } & \multicolumn{2}{|c|}{ - Insulin } & \multicolumn{2}{|c|}{+ Insulin } \\
\hline & Mean & SE & Mean & SE & Mean & SE & Mean & SE & Mean & SE & Mean & SE \\
\hline $\begin{array}{l}\text { Basal incorporation } \\
(\mu \mathrm{g} \text { atoms } \mathrm{C} / \mathrm{min} \\
\text { per } \mathrm{g} \text { dry wt) }\end{array}$ & 1.03 & $0 \cdot 19$ & . & & $0 \cdot 19^{* *}$ & 0.05 & . & . & $0-09^{* *}$ & 0.06 & . & . \\
\hline \multicolumn{13}{|c|}{$\begin{array}{l}\text { Incorporation in the presence of additions } \\
\text { (percentage of basal incorporation) }\end{array}$} \\
\hline None & 100 & & 132 & 5 & 100 & . & 227 & 36 & 100 & . & 144 & 33 \\
\hline High-Cr anionic & 91 & 6 & 131 & 2 & 142 & 48 & 260 & 5 & . & . & . & . \\
\hline Low-Cr anionic & & . & 128 & 2 & & & . & . & . & . & . & . \\
\hline High-Cr DEB & 118 & 5 & $246+t$ & 27 & 93 & 14 & $374 \dagger$ & 33 & 113 & 22 & $278 \dagger$ & 58 \\
\hline Low-Cr DEB & 154 & 25 & $319+\dagger$ & 27 & 84 & 2 & $345 \dagger$ & 24 & & . & . & . \\
\hline High-Cr Cl & 163 & 30 & $374+5$ & 33 & 167 & 44 & $389 \dagger$ & 59 & 132 & 46 & 213 & 50 \\
\hline Low-Cr C1 & - & . & $358 \dagger \dagger$ & 40 & . & . & . & . & . & . & . & . \\
\hline High-Cr Nl & & . & 113 & 14 & . & . & . & . & . & . & . & . \\
\hline Low-Cr N1 & 125 & 15 & 131 & 17 & . & . & . & 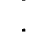 & . & . & . & . \\
\hline $100 \mathrm{~nm}$-insulin & . & . & $214 \dagger$ & 15 & . & . & 276 & 45 & . & . & $243 \uparrow$ & 20 \\
\hline
\end{tabular}

+ , With; - , without; DEB, C1, N1, fractions obtained from brewer's yeast (for details, see Fig. 1).

Mean value was significantly different from that found for cells from animals reared on a normal diet (by Student's $t$ test for paired values): ${ }^{* *} P<0.005$.

Mean value was significantly different from that found in the presence of $4 \mathrm{~nm}$-insulin without yeast fraction for cells from animals fed on the same diet (by Student's $t$ test for paired values): $\uparrow P<0.05, \dagger+P<0.005$.

$\ddagger$ For details of diets, see pp. 624-625.

response to insulin, and a 'cationic' fraction $\mathrm{C} 1$ which did enhance the response to insulin. The DEB and $\mathrm{Cl}$ fractions contributed up to $3 \mathrm{~mm}$-amino acids when added to the hepatocyte incubations, and these amino acids may account for the effects in the absence of insulin (Katz et al. 1976).

The response of hepatocytes to fractions from the low-Cr yeast culture was similar to the response to fractions from the high- $\mathrm{Cr}$ culture, and the insulin-enhancing activity was recovered in the same $\mathrm{Cl}$ fraction. Further fractionation of the high- and low-Cr $\mathrm{Cl}$ fractions on ion-exchange resins and thin-layer chromatography resulted in identification of the substance responsible for the insulin-enhancing activity as $\gamma$-aminobutyric acid which contained no detectable Cr (Holdsworth \& Neville, 1988).

\section{Effects of yeast fractions on hepatocytes from rats reared on a low-Cr diet}

Rats reared on the low-Cr diet grew more slowly than those on the normal diet, i.e. $2.9(\mathrm{SE} 0.2)$ and 4.1 (SE 0.2) $\mathrm{g} / \mathrm{d}$ respectively. Hepatocytes from rats reared on the low-Cr diet incorporated glucose-C into glycogen at a much lower rate than did hepatocytes from normally fed rats (Table 1). The percentage stimulation by insulin and yeast fractions was greater than that seen with normal hepatocytes, but the increase did not bring the absolute rate up to the level seen in normal hepatocytes. Effects of high-Cr and low-Cr yeast fractions were similar. Supplementation of the low-Cr diet with $\mathrm{Cr}(1 \mathrm{mg} / \mathrm{kg}$ diet) did not alter the response of the hepatocytes (Table 1) and did not alter the growth rate.

No differences were found in metabolite levels in hepatocytes from animals which had 
Table 2. Glycogen synthetase (EC 2.4.1.11) activity of hepatocytes from rats which had been raised on various diets $\dagger$

(Results are given as means with their standard errors; no. of replicates 6-10)

\begin{tabular}{|c|c|c|c|c|c|c|c|}
\hline \multirow[b]{3}{*}{ Additions } & \multirow{2}{*}{\multicolumn{2}{|c|}{$\begin{array}{l}\text { Total activity } \\
(a+b)(\mu \mathrm{mol} / \mathrm{min} \\
\text { per g dry wt })\end{array}$}} & \multirow{2}{*}{\multicolumn{2}{|c|}{$\begin{array}{l}\text { Percentage in } a \\
\text { form }\left(\frac{a}{a+b} \times 100\right)\end{array}$}} & \multicolumn{3}{|c|}{$\begin{array}{l}\text { Percentage in } a \text { form (\% } \\
\text { of control) }\end{array}$} \\
\hline & & & & & \multirow{2}{*}{$\frac{- \text { Insulin }}{\text { Mean }}$} & \multicolumn{2}{|c|}{+ Insulin } \\
\hline & Mean & $\mathrm{SE}$ & Mean & $\mathrm{SE}$ & & Mean & SE \\
\hline \multicolumn{8}{|l|}{ Normal diet } \\
\hline None & 0.79 & 0.07 & 38 & 5 & 100 & 110 & 5 \\
\hline High-chromium DEB & . & . & . & . & & $136^{* *}$ & 8 \\
\hline High-Cr Cl & . & . & . & . & 102 & $148^{* *}$ & 16 \\
\hline High-Cr N1 & . & . & . & . & . & 90 & 6 \\
\hline \multicolumn{8}{|l|}{ Low-Cr diet } \\
\hline None & $0 \cdot 87$ & $0 \cdot 15$ & 33 & 4 & 100 & 110 & 3 \\
\hline High-Cr DEB & $\cdot$ & . & . & . & - & $139 * *$ & 9 \\
\hline
\end{tabular}

+, With; -, without; DEB, Cl, N1, fractions obtained from brewer's yeast (for details, see Fig. 1).

Mean value was significantly different from that found in the presence of $4 \mathrm{~nm}$-insulin without yeast fraction for cells from animals fed on the same diet: ${ }^{* *} P<0 \cdot 01$.

$\dagger$ For details of diets, see pp. 624-625.

been fed on the normal and low-Cr diets: glycogen 536 (SE 35) and 509 (SE 73) $\mu$ mol glucose residues/g dry weight respectively, ATP 8.9 (SE 0.3$)$ and 8.4 (SE 0.5$) \mu \mathrm{mol} / \mathrm{g}$ dry weight respectively.

\section{Glycogen synthetase activity}

Table 2 shows that the total $(a+b)$ activity of glycogen synthetase in hepatocytes prepared from normal rats was close to that found in hepatocytes from rats reared on the low-Cr diet, and that the percentage in the $a$ form was similar. In both cases incubation with 4 nMinsulin slightly increased the percentage in the $a$ form, and those yeast fractions which enhanced insulin-dependent incorporation of glucose- $\mathrm{C}$ into glycogen also increased the percentage of glycogen synthetase in the $a$ form when they were incubated in the presence of insulin but not when incubated in the absence of insulin. There was no difference between the glucose-6-phosphate content of extracts of cells from animals fed on rat cubes or on the low-Cr diet (1.46 (SE 0.15) and 1.22 (SE 0.04) $\mu \mathrm{mol} / \mathrm{g}$ dry weight respectively).

\section{DISCUSSION}

The present study has shown that some yeast fractions enhance incorporation of glucose$\mathrm{C}$ into glycogen by hepatocytes in the presence of insulin, but have smaller effects in the absence of insulin. This increased incorporation may be explained by the effect of the yeast fractions on glycogen synthetase activity. Fraction $\mathrm{C} 1$ shares some of the properties which have been reported for GTF as it contains water-soluble, cationic material of the same molecular size, and a fraction prepared in a similar way was previously found to enhance the response to insulin by adipocytes (Davies et al. 1985). However the effects on hepatocytes do not appear to be dependent on $\mathrm{Cr}$, as yeast fractions were equally effective in enhancing the response to insulin when extracted from high- or low-Cr yeast, and were equally effective on hepatocytes isolated from normal rats and from rats which had been reared on a low- $\mathrm{Cr}$ diet with or without $\mathrm{Cr}$ supplementation.

The rats which were reared on the low-Cr diet showed a lower than normal growth rate, 
and the hepatocytes incorporated glucose- $\mathrm{C}$ into glycogen at a lower than the normal basal rate. These defects do not appear to be due to a lack of $\mathrm{Cr}$ in the diet since development of the defects was not prevented by addition of $\mathrm{Cr}$ salts to the low-Cr diet. They may well be due to the large difference in composition between rat cubes and the low-Cr diet. As mentioned earlier (see Experimental methods), our procedures may not have produced severe depletion of $\mathrm{Cr}$ in rats, but failure of $\mathrm{Cr}$ to restore the growth rate of severely depleted rats which had been reared on a low-Cr diet under strictly controlled environmental conditions has been reported (Schroeder, 1966).

The defect in incorporation of glucose-C into glycogen was surprising, as the hepatocytes from rats fed on the low-Cr diet contained normal levels of glycogen, and the glycogen synthetase activity was normal. Preliminary experiments suggest that the relative importance of gluconeogenesis and phosphorylation of glucose for production of glucose6-phosphate and glycogen may be different in cells from rats fed on rat cubes and low-Cr diets. While the cells from animals fed on the low- $\mathrm{Cr}$ diet incorporated glucose- $\mathrm{C}$ into glycogen more slowly than did cells from normal animals, they incorporated $\mathrm{H}^{14} \mathrm{CO}_{3}{ }^{-}$(in the presence of unlabelled lactate and glucose) faster than did cells from normal animals (Holdsworth \& Neville, 1988). Thus there may have been comparatively low glucose utilization by liver in vivo in the rats fed on the low-Cr diet, and this may contribute to low glucose tolerance on that diet. Comparatively recent work suggests that various highsucrose, low-Cr diets produce only mild impairment of glucose tolerance (Wooliscroft \& Barbosa, 1977; Shah et al. 1977; Jain et al. 1981; Donaldson et al. 1985), similar to the mild effects originally reported (Mertz, 1976), and that this defect is not abolished by $\mathrm{Cr}$ supplementation (Jain et al. 1981; Donaldson et al. 1985), and may be due to some feature of the diet other than the low Cr level (Donaldson et al. 1985; Offenbacher \& Pi-Sunyer, 1988).

The present work has produced evidence that brewer's yeast extract contains material which enhances the effect of low concentrations of insulin on glucose- $\mathrm{C}$ incorporation into glycogen. This material may contribute to the reported beneficial effects of dietary yeast supplements on glucose tolerance. Further fractionation of the extract showed that the active substance was $\gamma$-aminobutyric acid (GABA) (Holdsworth \& Neville, 1988). This action of GABA may partly account for effects attributed to the postulated GTF. The experiments were designed to detect yeast $\mathrm{Cr}$ complexes and their effects on hepatocyte metabolism, but no evidence has been found for an involvement of $\mathrm{Cr}$ in the process studied, although effects of brewer's yeast extracts differing more than 100 -fold in $\mathrm{Cr}$ content were tested on cells from animals which had been reared on either a normal diet or a low-Cr diet with or without added $\mathrm{Cr}$. It is possible that other procedures might detect $\mathrm{Cr}$ complexes active in the liver. Both $\mathrm{Cr}$-containing (Toepfer et al. 1977) and $\mathrm{Cr}$-free (Davies et al. 1985) yeast fractions have been reported to enhance the effects of low concentrations of insulin on glucose utilization by isolated adipose tissue preparations, and fractions with insulin-like activity have also been found (Hwang et al. 1987; Tokuda et al. 1987). However, adipose tissue may use only a small part of a glucose load in vivo, so that effects on adipose tissue may not be sufficient to explain effects on glucose tolerance in vivo. As the work reported here failed to detect a $\mathrm{Cr}$ effect on liver, which has a special role in glucose homeostasis, the possibility of a role of $\mathrm{Cr}$ on glucose metabolism in muscle, which is the major site of glucose utilization in vivo, should be investigated.

The authors thank the Australian Sugar Industry and the Australian Brewers' Association for financial support. The authors also thank Mrs R. Thomson for technical assistance and Dr J. J. Fardy, CSIRO Division of Energy Chemistry, NSW, for the neutron activation analysis. 


\section{REFERENCES}

Anderson, R. A., Brantner, J. H. \& Polansky, M. M. (1978). An improved assay for biologically active chromium. Journal of Agricultural and Food Chemistry 26, 1219-1221.

Bergmeyer, H. V. (1974). Methods of Enzymatic Analysis, 2nd ed. London \& New York: Academic Press.

Davidson, M. B. (1981). Autoregulation by glucose of hepatic glucose balance: permissive effect of insulin. Metabolism 30, 279-284.

Davies, D. M., Holdsworth, E. S. \& Sherriff, J. L. (1985). The isolation of glucose tolerance factors from brewer's yeast and their relationship to chromium. Biochemical Medicine 33, 297-311.

Donaldson, D. L., Lee, D. M., Smith, C. C. \& Rennert, O. M. (1985). Glucose tolerance and plasma lipid distributions in rats fed a high-sucrose, high-cholesterol, low-chromium diet. Metabolism 34, 1086-1093.

Holdsworth, E. S. \& Appleby, G. J. (1984). Assays of glucose tolerance factor and its mode of action, studied with brewer's yeast. Journal of Inorganic Biochemistry 21, 31-44.

Holdsworth, E. S. \& Neville, E. (1988). Extracts of brewer's yeast contain GABA which enhances activation of glycogen synthetase by insulin in isolated rat hepatocytes. Biochemistry International 17, 1107-1116.

Hwang, D. L., Lev-Ran, A., Papoian, T. \& Beech, W. K. (1987). Insulin-like activity of chromium-binding fractions from brewer's yeast. Journal of Inorganic Biochemistry 30, 219-225.

Jain, R., Verch, R. L., Wallach, S. \& Peabody, R. A. (1981). Tissue chromium exchange in the rat. American Journal of Clinical Nutrition 34, 2199-2204.

Katz, J., Golden, S. \& Wals, P. A. (1976). Stimulation of hepatic glycogen synthesis by amino acids. Proceedings of the National Academy of Sciences, USA 73, 3433-3437.

Krebs, H. A., Cornell, N. W., Lund, P. \& Hems, R. (1974). Isolated liver cells as experimental material. In Alfred Benzon Symposium, vol. 6, pp. 726-750 [F. Lindquist and N. Tygstrup, editors]. Copenhagen: Munksgaard.

Lee, E. Y. C. \& Whelan, W. J. (1966). Enzymic methods for the micro-determination of glycogen and amylopectin, and their unit chain lengths. Archives of Biochemistry and Biophysics 116, 162-167.

Mertz, W. (1976). Chromium and its relation to carbohydrate metabolism. Medical Clinics of North America $\mathbf{6 0}$, 739-744.

Mertz, W., Toepfer, E. W., Roginski, E. E. \& Polansky, M. M. (1974). Present knowledge of the role of chromium. Federation Proceedings 33, 2275-2280.

Mokrasch, L. C. (1967). Use of 2,4,6-trinitrobenzene-sulfonic acid for the coestimation of amines, amino acids and proteins in mixtures. Analytical Biochemistry 18, 64-71.

Offenbacher, E. G. \& Pi-Sunyer, F. X. (1988). Chromium in human nutrition. Annual Review of Nutrition 8, $543-563$.

Schwarz, K. (1951). Production of dietary necrotic liver degeneration using American Torula yeast. Proceedings of the Society for Experimental Biology and Medicine 77, 818-823.

Schwarz, K. \& Mertz, W. (1959). Chromium (III) and the glucose tolerance factor. Archives of Biochemistry and Biophysics 85, 292-295.

Schroeder, H. A. (1966). Chromium deficiency in rats: a syndrome simulating diabetes mellitus with retarded growth. Journal of Nutrition 88, 439-445.

Shah, J. H., Wongsurawat, N., Aran, P. P., Motto, G. S. \& Bowser, E. N. (1977). A method for studying acute insulin secretion and glucose tolerance in unanaesthetised and unrestrained rats: the effect of mild stress on carbohydrate metabolism. Diabetes 26, 1-6.

Sherriff, J. L. (1983). GTF activity in adipocytes. MSc Thesis, University of Tasmania.

Thomas, J. A., Schlender, K. K. \& Larner, J. (1968). A rapid filter paper assay for UDPglucose-glycogen glucosyl transferase, including an improved biosynthesis of UDP. ${ }^{14} \mathrm{C}$-glucose. Analytical Biochemistry $25,486-499$.

Toepfer, E. W., Mertz, W., Polansky, M. M., Roginski, E. E. \& Wolf, W. R. (1977). Preparation of chromiumcontaining material of glucose tolerance factor activity from brewer's yeast and by synthesis. Journal of Agricultural and Food Chemistry 25, 162-166.

Tokuda, M., Kashiwagi, A., Wakamiya, E., Oguni, T., Mino, M. \& Kagamiyama, H. (1987). Glucose tolerance factor stimulates 3-O-methylglucose transport into isolated adipocytes. Biochemical and Biophysical Research Communications 144, 1237-1242.

Vinson, J. A. \& Bose, P. (1984). The effect of a high-chromium yeast on the blood glucose control and blood lipids of normal and diabetic human subjects. Nutrition Reports International 30, 9l1-918.

Vinson, J. A. \& Hsaio, K.-H. (1985). Comparative effect of various forms of chromium on serum glucose: an assay for biologically active chromium. Nutrition Reports International 32, 1-7.

Wallach, S. (1985). Clinical and biochemical aspects of chromium deficiency. Journal of the American College of Nutrition 4, 107-120.

Wooliscroft, J. \& Barbosa, J. (1977). Analysis of chromium induced carbohydrate intolerance in the rat. Journal of Nutrition 107, 1702-1706. 